\title{
Lactobacillus reuteri 15007 modulates tight junction protein expression in IPEC-J2 cells with LPS stimulation and in newborn piglets under normal conditions
}

Fengjuan Yang ${ }^{1}$, Aina Wang ${ }^{2}$, Xiangfang Zeng ${ }^{1}$, Chengli Hou ${ }^{1}$, Hong Liu ${ }^{1}$ and Shiyan Qiao ${ }^{1 *}$

\begin{abstract}
Background: Tight junctions (TJS) maintain the intestinal mucosal barrier, dysfunction of which plays a vital role in the pathophysiology of a variety of gastrointestinal disorders. Previously, we have shown that L. reuteri 15007 maintained the gut epithelial barrier in newborn piglets. Here we aimed to decipher the influence of L. reuteri 15007 on tight junction (TJ) protein expression both in vivo and in vitro.

Results: We found that L. reuteri 15007 significantly increased the protein abundance of intestinal epithelial claudin-1, occludin and zonula occluden-1 (ZO-1) in newborn piglets (orally administrated with $6 \times 10^{9}$ CFU of L. reuteri 15007 daily for 14 days). In vitro, treatment with L. reuteri 15007 alone maintained the transepithelial electrical resistance (TEER) of IPEC-J2 cells with time. In addition, IPEC-J2 cells were stimulated with $1 \mu \mathrm{g} / \mathrm{mL}$ lipopolysaccharide (LPS) for 1, 4, 8, 12 or $24 \mathrm{~h}$, following pre-treatment with L. reuteri 15007 or its culture supernatant for $2 \mathrm{~h}$. The results showed that LPS time-dependently induced (significantly after 4 or 8 h) the expression of TNF-a and IL-6, and decreased TJ proteins, which was reversed by pre-treatment of $L$. reuteri 15007 or its culture supernatant.
\end{abstract}

Conclusions: L. reuteri 15007 had beneficial effects on the expression of TJ proteins in newborn piglets and the in-vitro results showed this strain had a positive effect on TEER of cells and inhibited the reduction of TJ proteins expression induced by LPS. These findings indicated L. reuteri 15007 may have potential roles in protection TJ proteins in TJ-deficient conditions.

Keywords: Lactobacillus, Newborn piglets, Tight junction, IPEC-J2, Lipopolysaccharides

\section{Background}

Diarrheal diseases in animals cause the livestock industry great economic loss and also represent a serious threat to farm animal welfare [1]. One of the main causes of diarrhea is gastrointestinal disorder and intestinal mucosa barrier dysfunction or "leaky gut" is reported to play a vital role in the pathophysiology of a variety of gastrointestinal disorders [2].

The intestinal mucosal barrier is maintained by tight junctions (TJs) [3], which are multiprotein complexes located around the apical end of the lateral membrane of

\footnotetext{
* Correspondence: qiaoshy@mafic.ac.cn

'State Key Laboratory of Animal Nutrition, China Agricultural University, Beijing 100193, China

Full list of author information is available at the end of the article
}

the epithelial cells and seal the paracellular space between adjacent epithelial cells [4]. TJs function as a selective/semipermeable paracellular barrier, which regulates the transport of ions, water and solutes through the paracellular pathway $[5,6]$. The most important and critical components in the structural and functional organization of the TJs are occludin, zonula occluden-1 (ZO-1) and claudin-1 [7-9]. The importance of these TJ proteins has been demonstrated under many conditions. For example, increased intestinal permeability, which is thought to increase the load of bacterial and dietary antigens in the lamina propria, has been observed in early weaned pigs (21 days of age) apparently due to aberrant expression of the essential TJ proteins [10]. Hence, modulation of $\mathrm{TJ}$ function, particularly through increasing levels 
of occludin, ZO-1 and claudin-1, is a target for novel therapeutic or prophylactic treatments against a range of diseases.

Probiotics, defined as live microorganisms which, when consumed in adequate amounts as part of food, confer a health benefit on the host [11], are widely used in humans and animals. Since the European Union banned the use of antibiotics as growth promoters in 2006, the use of probiotic animal feed additives has increased as reported both in vivo $[12,13]$ and in vitro $[14,15]$. Ingestion of probiotics has been shown to prevent or treat a variety of gut disorders [16,17], although the mechanisms through which they function are not completely known. However, a large amount of evidence suggests that one mechanism may be via protection or augmentation of the intestinal mucosal barrier function $[17,18]$.

Lactobacillus, one of the most commonly used probiotic microorganisms $[19,20]$, frequently occurs in the intestinal microflora of various vertebrates and exerts Lactobacillus-mediated barrier protection via modulation of TJs [21-23]. Previous studies have demonstrated that this genus significantly reduces the incidence and the severity of diarrhea [24] and helps maintain a functional mucosal barrier [25].

To test the hypothesis that natural Lactobacillus found in animal intestinal tract may be a potential source of probiotic bacteria for livestock. In 2003, our group isolated thousands of strains of Lactobacillus from the gastrointestinal tract GIT of eleven healthy weaned piglets from different pig farms. According to criteria including tolerance to heat, low $\mathrm{pH}$, and bile salts, as well as storage stability and antagonism to pathogenic agents, four strains, Lactobacillus fermentum I5007, L. gasseri S1031, L. reuteri $\mathrm{I} 2021$ and L. acidophilus I021, were selected [26]. Subsequently, a series of in vivo and in vitro studies demonstrated that L. fermentum 15007 had the greatest adhesion [27], and showed beneficial effects on growth performance and antioxidative activity, as well as modulation of intestinal microbiota and mucin secretion in piglets [28-30]. Summarily, our work in the past decade indicates that $L$. fermentum I5007, now known as $L$. reuteri 15007 according whole-genome sequence of this strain [31], can be used as a potential probiotic. Recently, our group found that oral administration of $L$. reuteri $\mathrm{I} 5007$ favored intestinal development and maintained the gut epithelial barrier in neonatal piglets [28]. However, the mechanism through which it exerts functions on the gut epithelial barrier is not fully understood. The aim of the present study was to evaluate $L$. reuteri I5007-mediated intestinal mucosal barrier augmentation in a newborn piglet model and investigate the mechanism for modulation of $\mathrm{TJ}$ s in a porcine jejunal epithelial cell line (IPEC-J2) challenged by lipopolysaccharides (LPS).

\section{Results}

Oral administration of $L$. reuteri 15007 enhanced the protein abundance of intestinal epithelial TJs in newborn piglets

Twelve male newborn piglets (4 days old) were orally administrated with $0.1 \%$ sterile peptone solution (the control group) or $6 \times 10^{9} \mathrm{CFU}$ of $L$. reuteri $\mathrm{I} 5007$ (the $L$. reuteri $\mathrm{I} 5007$ group) daily for 14 days. The expression of TJ protein claudin-1, occludin and ZO-1 both in the jejunal and ileal epithelium were measured using immunoblotting to investigate the effect of L. reuteri I5007 on TJ function. Compared with control group, no significant difference was observed in the jejunal epithelial claudin-1 expression in the L. reuteri 15007 group, while oral administration of $L$. reuteri $\mathrm{I} 5007$ significantly increased the protein abundance of occludin and ZO-1 in jejunal epithelium of piglets (Figure 1A). However, all

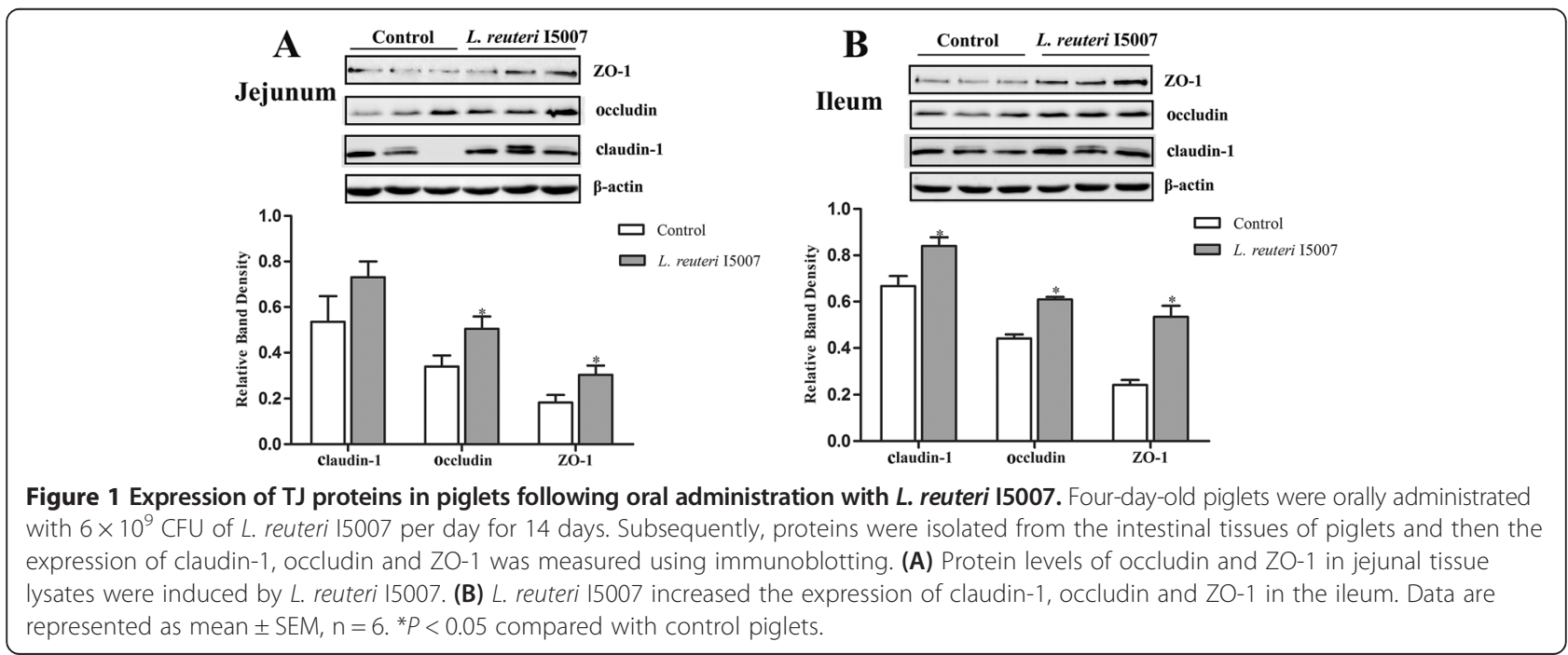


levels of these TJ proteins were distinctly higher in the ileum of piglets administrated with $L$. reuteri 15007 than those of control piglets (Figure 1B).

\section{L. reuteri 15007 maintained transepithelial electrical resistance (TEER) of IPEC-J2 cells}

IPEC-J2 cell monolayers cultured for complete confluence were treated with $L$. reuteri 15007 cells $\left(3 \times 10^{7} \mathrm{CFU} / \mathrm{mL}\right)$ and TEER values were measured every two hours for $10 \mathrm{~h}$ (Figure 2). When compared with the untreated control, treatment with $L$. reuteri 15007 had no effect on TEER of IPEC-J2 cells during $0-2 \mathrm{~h}$, but did lead to significantly higher values of TEER during 4-10 h. On the whole, an $8.67 \%$ decline of TEER values was caused during $10 \mathrm{~h}$ of the measurement, as seen for the control, while coincubation with $L$. reuteri 15007 showed almost no decline (a $0.86 \%$ decline) in TEER values, indicating that $L$. reuteri I5007 had a positive maintaince on TEER of IPEC-J2 cells with time.

\section{L. reuteri 15007 differentially affected LPS-induced TNF-a and IL-6 mRNA expression in IPEC-J2 cells}

To further elucidate the effects of L. reuteri 15007 on modulation of TJ function, the mRNA expression of inflammatory cytokines including TNF- $\alpha$ and IL- 6 was determined in IPEC-J2 cells treated with LPS for 1, 4, 8, 12 or $24 \mathrm{~h}$, following pre-treatment with L. reuteri 15007 for $2 \mathrm{~h}$. According to a previous study of our group, $L$. reuteri 15007 could behave strong adhesion ability to monolayer cells by co-culture with cells for $1 \mathrm{~h}$ [27]. Resta-Lener and Barrett [32] showed enteroinvasive Escherichia coli evoked fall in TEER was prevented if cell monolayers were pretreated with live probiotics, and was also partially attenuated by exposure simultaneously to probiotics and enteroinvasive E. coli, but not if the cells were infected with enteroinvasive $E$. coli for one hour and

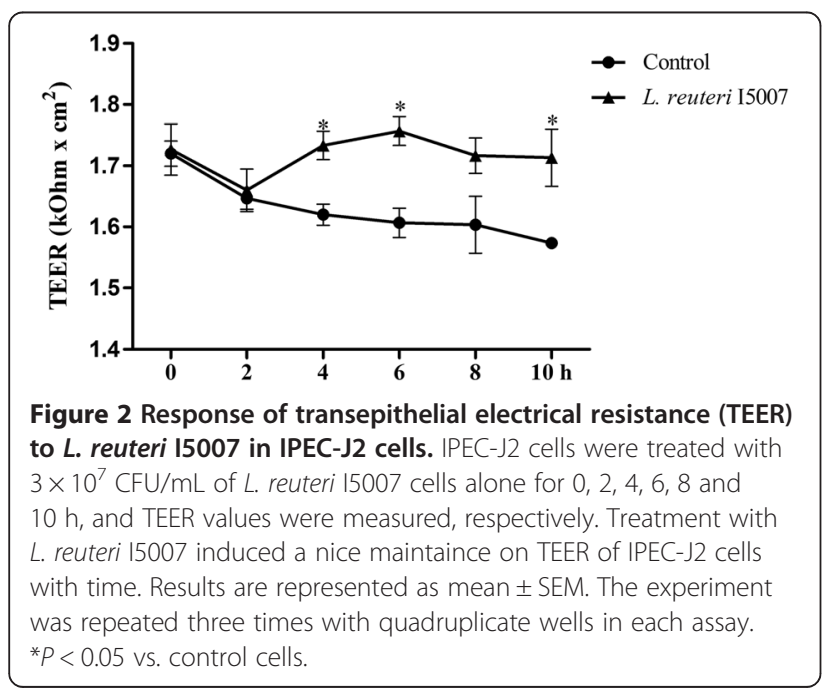

then exposed to probiotics. Considering these circumstances, to investigate the protect effects of $L$. reuteri I5007 on TJ proteins, we appropriately extended the incubation time for pretreatment with L. reuteri I5007 to $2 \mathrm{~h}$.

Figure 3A shows that LPS significantly increased TNF$\alpha$ mRNA expression after $4 \mathrm{~h}$, but not at $1 \mathrm{~h}$. No significant differences were observed in the mRNA expression of TNF- $\alpha$ at $1 \mathrm{~h}$ among different treatments. However, TNF- $\alpha$ mRNA expression in LPS-stimulated cells was time-dependently increased compared with the control treatment, while after $12 \mathrm{~h}$, the increase in TNF- $\alpha$ mRNA expression reached a plateau. Similarly, the mRNA expression of IL-6 (Figure 3B) was increased in IPEC-J2 cells treated with LPS after $8 \mathrm{~h}$ and was maintained until $12 \mathrm{~h}$ treatment. Collectively, treatment with

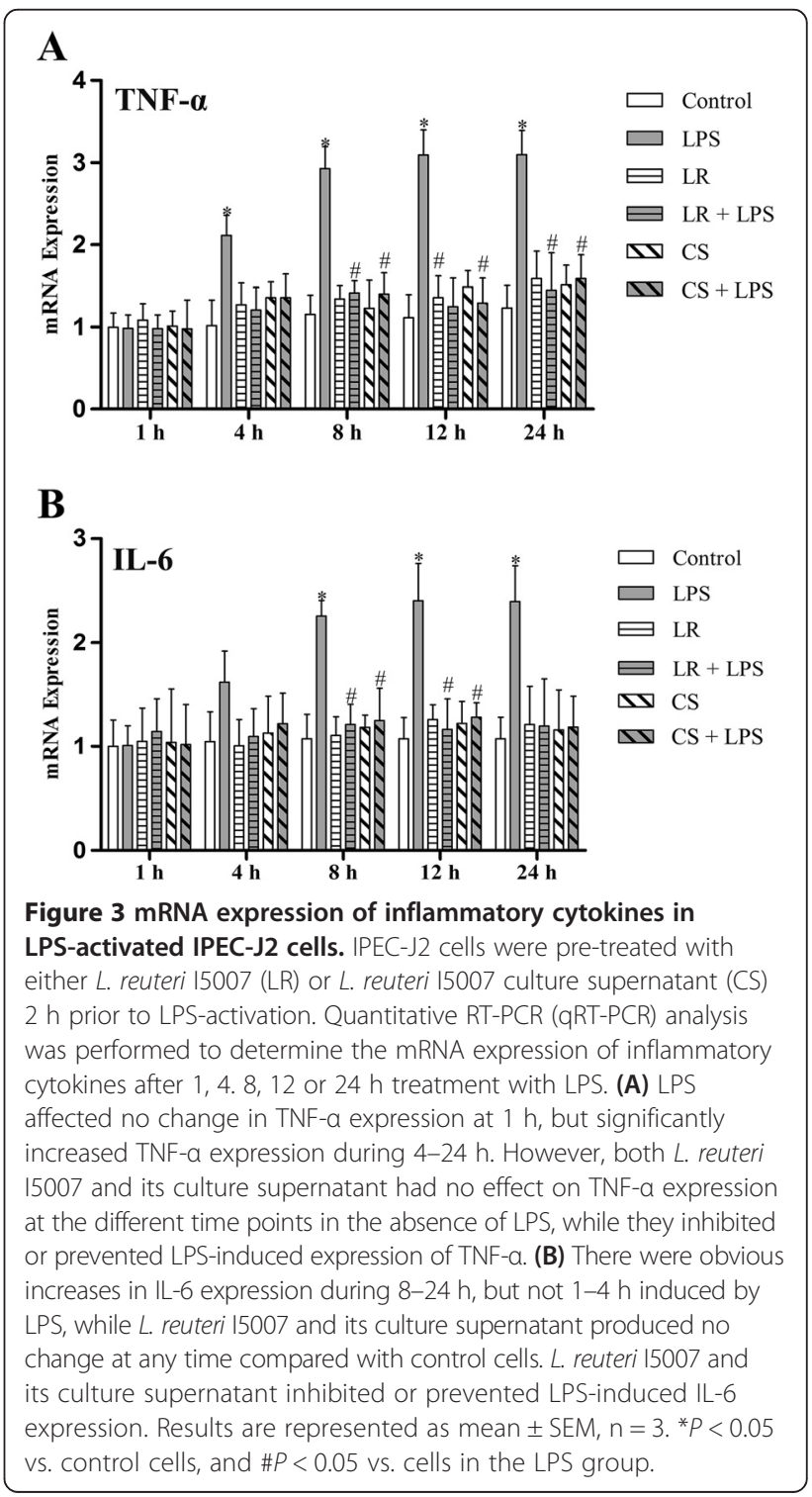


L. reuteri $\mathrm{I} 5007$ in the absence of LPS had no effect on mRNA levels of TNF- $\alpha$ and IL- 6 compared with the control group at different time points. However, in the presence of LPS, L. reuteri 15007 significantly decreased the mRNA expression of these two inflammatory cytokines, compared with the LPS group after $8 \mathrm{~h}$.

\section{L. reuteri 15007 augmented LPS-induced TJ protein expression in IPEC-J2 cells}

We further investigated the mRNA expression of claudin-1, occludin and ZO-1 in inflamed cultured intestinal cells. Treatment of IPEC-J2 cells with $1 \mu \mathrm{g} / \mathrm{mL}$ LPS had no effect on the mRNA expression of claudin-1 and ZO-1 during $1-4 \mathrm{~h}$, but showed a significant decline during 8-24 h (Figure 4A and C). Similarly, compared with the control treatment, LPS time-dependently reduced occludin mRNA expression. In detail, no difference at $1 \mathrm{~h}$, but decreases during 4-24 h (Figure 4B). However, there was no significant change in mRNA expression of all three $\mathrm{TJ}$ proteins in the other four groups versus the control group. Pre-treatment with $L$. reuteri 15007 significantly mitigated or prevented the reduction of mRNA expression of all three TJ proteins induced by LPS.

We used immunoblotting to investigate the protein abundance of claudin-1, occludin and ZO-1. In agreement with the observation of mRNA expression of these TJ proteins, there was no significant difference in the levels of these TJ proteins in the other four groups (except for the LPS group) compared with the control group (Figure 5). However, LPS stimulation robustly decreased the levels of claudin-1, occludin and ZO-1 during 4-24 h (Figure 5B-E), but not at $1 \mathrm{~h}$ (Figure 5A). Treatment of IPEC-J2 cells using L. reuteri 15007 markedly induced higher levels of these proteins than those in cells treated with LPS during 4-24 h.

\section{L. reuteri 15007 culture supernatant differentially affected LPS-induced inflammatory cytokine and specific TJ protein expression in IPEC-J2 cells}

To further elucidate whether the culture supernatant was involved in L. reuteri I5007-mediated improvement in $\mathrm{TJ}$ function, the culture supernatant of $L$. reuteri I5007 was also added to pre-treat IPEC-J2 cells. Compared with the control group, cells treated with $L$. reuteri I5007 culture supernatant in the absence of LPS caused no significant change in TNF- $\alpha$ and IL- 6 mRNA expression. However, the culture supernatant of $L$. reuteri I5007 did reduce LPS-induced inflammatory cytokine expression during 8-24 h (Figure 3). In general, both mRNA expression and protein levels of claudin-1, occludin and ZO-1 in cells pre-treated with the culture supernatant of L. reuteri 15007 were higher than those in cells induced by LPS after 4 or 8 h (Figure 4 and Figure 5).

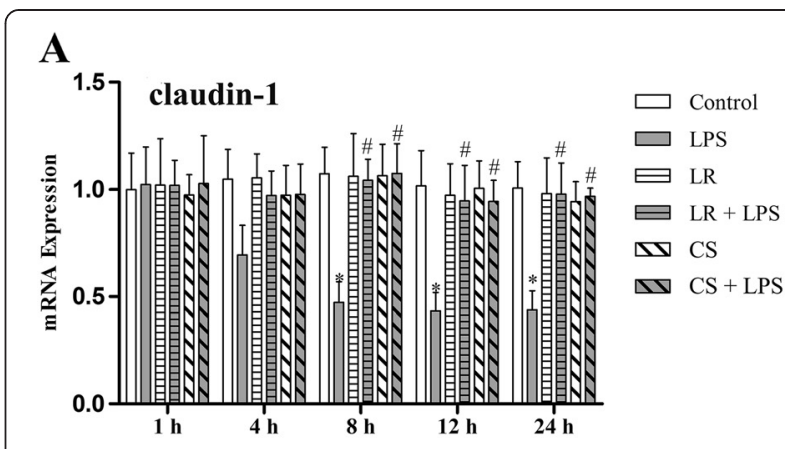

B

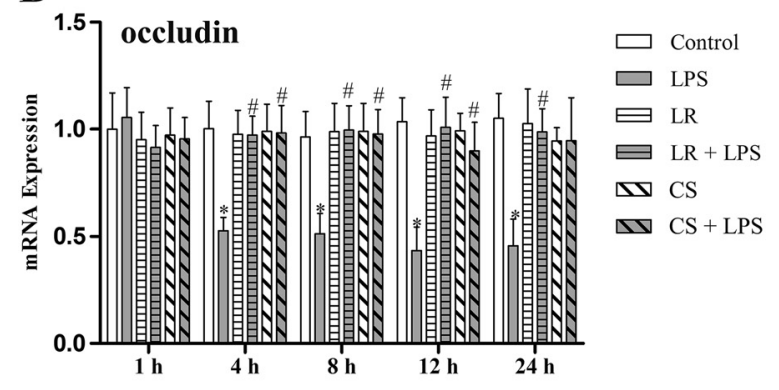

C

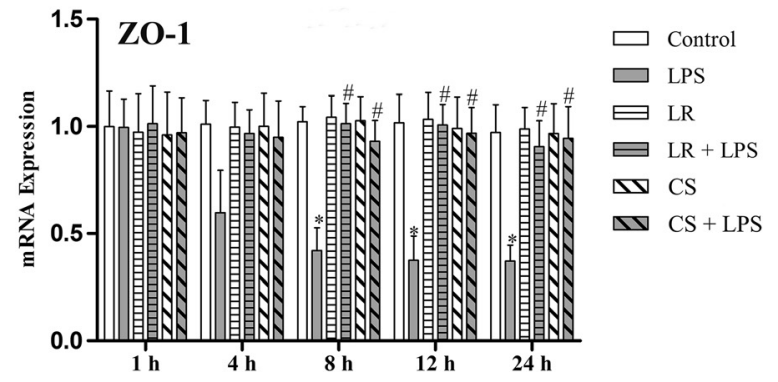

Figure 4 mRNA expression of TJ proteins in LPS-activated IPEC-J2 cells. (A) qRT-PCR analysis showed that LPS induced a decrease in mRNA expression of claudin-1 at 8, 12 and $24 \mathrm{~h}$, while L. reuteri 15007 (LR) and L. reuteri 15007 culture supernatant (CS) effectively inhibited LPS-induced expression of claudin-1. (B) There was no change in occludin expression at $1 \mathrm{~h}$, but a significant decrease after $4 \mathrm{~h}$ treatment with LPS. However, L. reuteri 15007 and its culture supernatant inhibited the decline. (C) LPS induced a distinct decrease in ZO-1 expression after $8 \mathrm{~h}$, which was inhibited by $L$. reuteri 15007 and its culture supernatant. Results are represented as mean $\pm \mathrm{SEM}, \mathrm{n}=3 .{ }^{*} P<0.05$ vs. control cells, and $\# P<0.05$ vs. cells in the LPS group.

\section{Discussion}

The defense response of the intestinal epithelium against pathogenic bacteria has been extensively explored, and evidence suggests that interactions between commensal bacteria and the host are involved in this process [33]. Thus, much attention has been paid to the effects of probiotics on gut barrier function. Some probiotics might improve or prevent gut barrier dysfunction caused by pathogenic bacteria or other toxic substances [22,23]. For example, L. plantarum significantly ameliorated 
$\mathbf{A}$
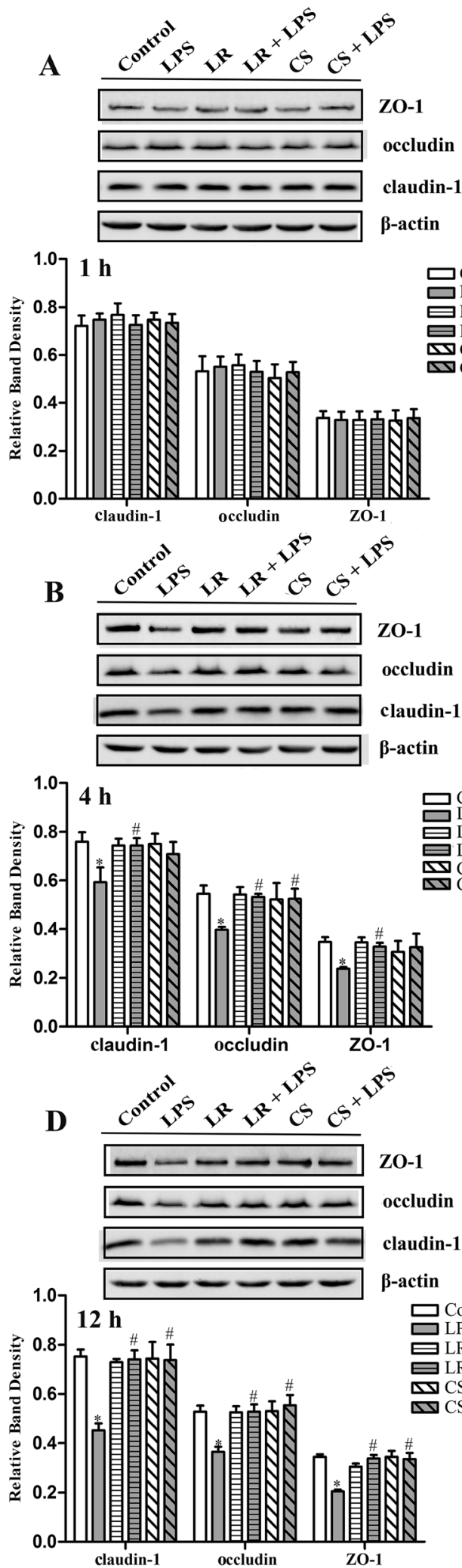

$\square$ Control

LPS

قLR + LPS

WS

$\underset{\mathrm{W} C S}{\mathrm{w}}+\mathrm{LPS}$
C

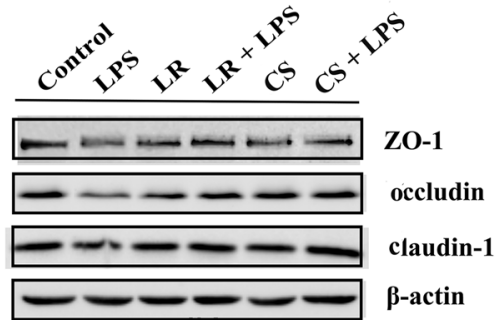

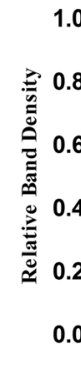
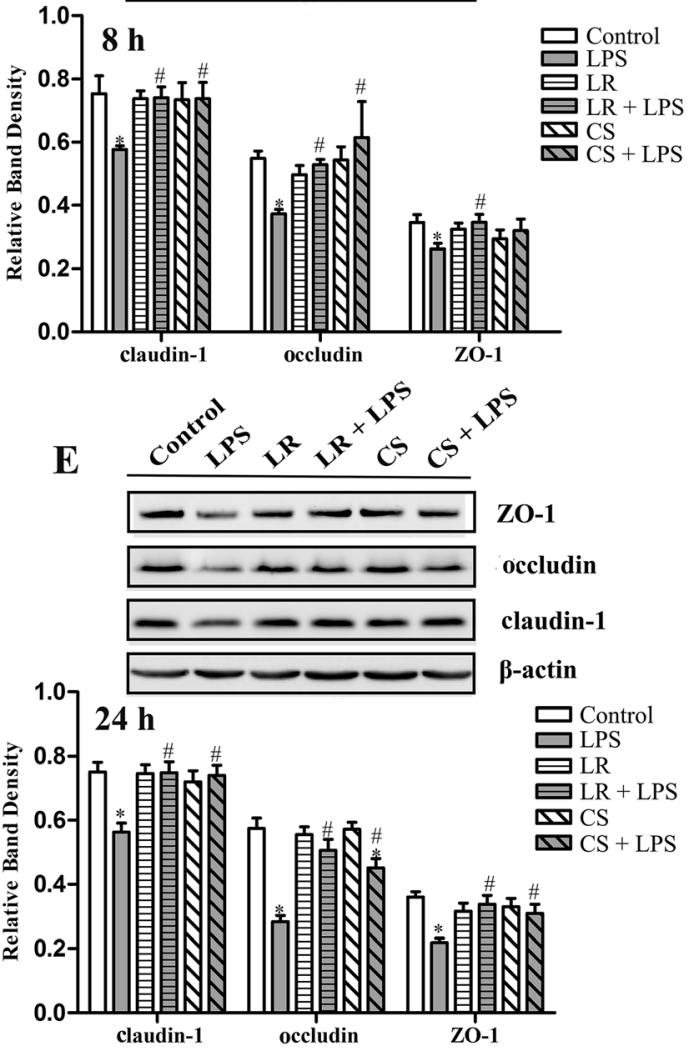

Figure $\mathbf{5}$ (See legend on next page.) 
(See figure on previous page.)

Figure $\mathbf{5}$ Levels of TJ proteins in LPS-activated IPEC-J2 cells at different time points. Proteins were isolated from IPEC-J2 cells and the expression of TJ proteins was assessed using immunoblotting. There was no significant difference in claudin-1, occludin and ZO-1 expression among the different treatments at $1 \mathrm{~h}$ (A). LPS produced decreases in all three TJ proteins at 4 (B), 8 (C), 12 (D) and 24 (E) h. Although L. reuteri 15007 (LR) and its culture supernatant (CS) had no effect on the levels of TJ proteins in the absence of LPS, they inhibited LPS-induced levels of TJ proteins. Results are represented as mean $\pm S E M, n=3 .{ }^{*} P<0.05$ vs. control cells, and $\# P<0.05$ vs. cells in the LPS group.

phorbol ester-induced ZO-1 and occludin redistribution and increased permeability in Caco-2 cells [34]. Therefore, although the mechanisms of action of probiotics may vary, the vital mechanism of probiotics is regulating the expression of $\mathrm{TJ}$ proteins.

The effects of probiotics on gut barrier in animal models are commonly studied in rodents. For example, L. helveticus and L. rhamnosus prevented chronic stress induced intestinal abnormalities in rats, which received 7 days of these strains in the drinking water prior to either a water avoidance stress or a sham stress for one hour per day for ten consecutive days and remained on these probiotics during the duration of the study [35]. However, reports in pigs, especially in neonatal piglets, are rare. In the present study, newborn piglets were selected to study the effects of L. reuteri 15007 on the expression of TJ proteins in the intestinal epithelium. We showed that L. reuteri 15007 up-regulated the expression of jejunal epithelial occludin and ZO-1, and ileal epithelial claudin-1, occludin and ZO-1 in young piglets, indicating $L$. reuteri 15007 effectively improved the intestinal mucosal barrier function of newborn piglets. This was consistent with an earlier study [36] showing that $L$. rhamnosus accelerated maturation of the intestinal mucosal barrier in mice via up-regulating the protein level of claudin-1. Oral administration of VSL\#3, a mixture of Streptococcus thermophilus, three strains of Bifidobacterium and four strains of Lactobacillus, in SAMP mice, obviously improved ileal epithelial permeability and increased the expression of occludin, but not claudin-1 or ZO-1 [21], which was not entirely consistent with our results. This might be due to different experimental conditions including strains of probiotic bacteria and animal models.

We next examined the effects of L. reuteri 15007 on the expression of inflammatory cytokines and specific TJ proteins in IPEC-J2 cells induced by LPS. LPS is an integral component of the gram-negative bacteria cell wall, capable of binding to Toll-like receptor-4 and activating a variety of protein kinase signaling pathways, subsequently generating inflammatory cytokines and other mediators [37]. Liu et al. [15] found that treatment of porcine intestinal epithelial cells (IPEC-J2) and rat intestinal epithelial cells (IEC-6) with LPS for $16 \mathrm{~h}$ markedly increased the secretion of IL-8, while co-culture with $L$. reuteri robustly inhibited LPS-induced overexpression of IL-8 in IPEC-J2 cells. In the present study, LPS induced increases in mRNA expression of TNF- $\alpha$ and IL-6 of IPEC-J2 cells after 4 or $8 \mathrm{~h}$, and pre-treatment with $L$. reuteri $\mathrm{I} 5007$ significantly suppressed LPS-induced TNF$\alpha$ and IL-6 expression. In addition, several studies have reported effects of probiotics on TNF- $\alpha$ and IL- 6 expression induced by LPS, but the regulatory action differs in different species or even different strains. For instance, L. reuteri ACTT 6475 greatly inhibited the generation of TNF in LPS-activated human monocytoid THP1 cells, as an immunosuppressive action [38]. In contrast, L. reuteri ACTT 55730 stimulated TNF- $\alpha$ production, as an immunostimulatory action [39]. Moreover, Rachmilewitz et al. [40] observed that co-culture of mice macrophages (isolated from Balb/c mice) with DNA of VSL\#3 bacteria significantly promoted IL- 6 production.

TJs, apical-most component of the junctional complex in epithelial cells, determine the selective permeability along the paracellular pathway. claudin-1, occludin and ZO-1 are critical components of the TJs [41]. LPS challenge resulted in a distinct decrease in the levels of $\mathrm{ZO}-1$ and $\mathrm{ZO}-2$, and induced the redistribution of $\mathrm{ZO}-2$ in human corneal epithelial cells [42]. Also, deterioration of the TJ proteins occludin and ZO-1 was observed in pulmonary cells of LPS-treated mice [43]. In agreement with previous studies, the present study found LPS reduced the levels of claudin-1, occludin and ZO-1 in IPEC-J2 cells. Our results also showed $L$. reuteri $\mathrm{I} 5007$ significantly attenuated the LPS-induced decline in claudin-1, occludin and $\mathrm{ZO}-1$ expression. In fact, one of the effects probiotics exert is to promote the integrity of the intestinal mucosal barrier by affecting the expression and structure of TJ proteins. An earlier study, conducted in dextran sodium sulfate-induced colitis in mice, demonstrated the probiotic mixture VSL\#3 prevented apoptosis and low expression of TJ proteins, and especially increased the ZO-1 level [44]. Khailova et al. [45] studied the effects of Bifidobacterium Bifidum in a rat model of necrotizing enterocolitis. The results showed that $B$. Bifidum improved intestinal integrity by normalizing the expression and localization of $\mathrm{TJ}$ and anherens junction proteins in the ileum compared to rats with neonatal necrotizing enterocolitis. Moreover, Lactobacillus and Bifidobacterium robustly suppressed $E$. coli-induced hyperpermeability and decreased ZO-1 expression in vitro [32].

A previous study showed that Lactobacillus and Bifidobacterium produced increases in the expression of the TJ proteins claudin-1 and occludin in normal human 
epidermal keratinocytes (NHEK) which had not been treated with any stressor [46]. However, it contrasts with our result that $L$. reuteri $\mathrm{I} 5007$ had no effect on the expression of specific TJ proteins in the absence of LPS. The in-vitro result seemingly showed differences from in-vivo finding that L. reuteri 5007 augmented TJ protein expression in piglets under normal conditions. It is well-known that GIT, in which microorganisms, toxins, digestive enzymes and other substances are all likely to cause damage, is the site of the largest and most complex environment in the mammalian host [47]. In this complex environment, piglets orally administrated with L. reuteri $\mathrm{I} 5007$ had higher expression of $\mathrm{TJ}$ proteins compared with control piglets which may be stimulated by complex factor in the GIT, indicating that $L$. reuteri I5007 exerted protective effects on TJs. In vitro, L. reuteri 15007 indeed prevented the LPS-induced decline in $\mathrm{TJ}$ protein expression, which further validated the protective effects of $L$. reuteri $\mathrm{I} 5007$ on TJ protein expression. Although L. reuteri 5007 behaved no effect in the absence of LPS, in-vitro results provide corroborative evidences that $L$. reuteri $\mathrm{I} 5007$ may play a positive role in protecting TJ proteins in dysfunctional or damaged GIT caused by pathogenic bacteria or other toxic substances $[32,44]$. In other words, in-vivo results together with invitro results imply that $L$. reuteri $\mathrm{I} 5007$ performs its protective effects by stabilization of synthesized TJ proteins or increasing new synthesis, and studies on a definite mechanism are needed.

TEER is a very important parameter of epithelial barrier function, which indicates variation of permeability and integrity of the cell monolayer $[48,49]$. In the present study, co-incubation with $L$. reuteri 15007 alone showed a nice maintaince on TEER of IPEC-J2 cells, consistent with an earlier study [46] showing that $L$. rhamnosus GG and B. longum increased TEER over control levels in NHEK cells. Furthermore, TEER in Caco-2 cells continued to decrease with time when treated with TNF- $\alpha$, while increased in L. plantarum + TNF- $\alpha$ [50]. We also found the effects of LPS and L. reuteri I5007 on inflammatory cytokines and specific TJ protein expression were time dependent. There was no difference in the expression of TNF- $\alpha$, IL- 6 and TJ proteins among the different groups at 1-4 h. However, TNF- $\alpha$ and IL-6 mRNA expression in LPS-mediated cells increased and the levels of TJ proteins decreased with time compared with control cells after 4 or $8 \mathrm{~h}$. Meanwhile, L. reuteri I5007 prevented the increased expression of TNF- $\alpha$ and IL- 6 and decreased expression of TJ proteins induced by LPS. These findings were supported by work conducted by Sheth et al. [50], which evaluated the effect of LPS in normal rat cholangiocyte monolayers and showed LPS produced a time-dependent effect on TJ integrity and barrier function. Moreover, in LPS-activated Caco-2 cells model, TEER was minimized at $1 \mathrm{~h}$ after treatment with LPS and was sustained after that, while co-culture of Lactobacillus after activation with LPS for $3 \mathrm{~h}$ boosted TEER over time and was maximized at 24 h [51].

In the past, only live microorganisms were thought to exert probiotic effects, which may be why probiotics were defined as 'live microorganisms which, when consumed in adequate amounts as part of food, confer a health benefit on the host' [11]. As the effective ingredients of probiotics have not been fully revealed, more and more studies are further exploring this issue. Heat-killed preparations of the probiotic L. rhamnosus GG accelerated intestinal barrier maturation and induced claudin-3 expression [36]. Furthermore, treatment of NHEK with lysates of Lactobacillus and Bifidobacterium for $24 \mathrm{~h}$ produced significant increases in TEER and levels of TJ proteins in NHEK, suggesting lysates of microorganisms also can exert probiotic effects [46]. This study also showed peptidoglycan, a major ligand of gram-positive bacteria, induced increased TEER in keratinocytes, in agreement with a previous study [52], together raising the interesting possibility that the cell wall components from probiotic lysates may at least partially be responsible for the changes in TJ function. Herein, our results showed the culture supernatant of L. reuteri $\mathrm{I} 5007$ (metabolites or secreted bioactive factors from $L$. reuteri I5007) obviously attenuated or prevented high expression of inflammatory cytokines and low levels of TJ proteins induced by LPS, indicating the culture supernatant of $L$. reuteri 15007 played a role in L. reuteri 15007 mediated improvement in TJ function. Similarly, secreted bioactive factors from $B$. infantis significantly increased TEER and levels of occludin and ZO-1 in T84 cells [53]. Therefore, the culture supernatant of $L$. reuteri I5007 had a similar effect of $L$. reuteri 15007 on modulation of inflammatory cytokine and TJ protein expression, implying that substances secreted by $L$. reuteri 15007 , including lactic acid, hydrogen peroxide, bacteriocin and exopolysaccharide, play a role in this effect. Whole genome sequencing result showed that genome of $L$. reuteri I5007 encoded two gene clusters for exopolysaccharide biosynthesis [31]. It may be proposed that secreted bioactive factors of $L$. reuteri $\mathrm{I} 5007$, especially exopolysaccharide interact with pattern recognition receptors of cells to induce activation of a series of signaling pathways [52] and subsequently regulate barrier function, including $\mathrm{TJ}$ function.

\section{Conclusions}

Taken together, the data presented here suggest that $L$. reuteri 15007 could effectively increase the levels of specific TJ proteins in the intestinal epithelium, thereby promoting maturation of the intestinal mucosal barrier in formula-fed piglets. L. reuteri I5007 maintained TEER 
of IPEC-J2 cells and mitigated and even prevented LPSinduced inflammatory cytokine and TJ protein expression, and the effects might be derived from its culture supernatant and were time dependent. Since $L$. reuteri I5007 has a positive effect on TJ protein expression, it is possible that this stain plays a potential role in treatment or prevention of intestinal epithelial TJs deficiency in mammals or human beings.

\section{Methods}

\section{Ethics statement}

All procedures used in this experiment complied with the Animal Care Protocol which was approved by the China Agricultural University Animal Care and Use Committee (Beijing, China).

\section{Preparation of bacteria}

L. reuteri $\mathrm{I} 5007$ was cultured to a stationary phase (about $24 \mathrm{~h}$ ) in sterile Man Rogosa Sharpe (MRS) medium at $37^{\circ} \mathrm{C}$ in an anaerobic environment, then centrifuged at $5,000 \times g$ for $10 \mathrm{~min}$ at $4^{\circ} \mathrm{C}$. For animal administration, the centrifugal cells were resuspended in reconstituted skim milk $(20 \% \mathrm{w} / \mathrm{v})$ and immediately freeze-dried. Plate counts showed the freeze-dried powder contained $6 \times 10^{9}$ colony forming units (CFU) of $L$. reuteri $\mathrm{I} 5007$ per gram. The bacteria powder was stored in sealed packets at a temperature of $4^{\circ} \mathrm{C}$ until used. During administration, $1 \mathrm{~g}$ of powder was dissolved in $3 \mathrm{~mL} 0.1 \%$ of sterile peptone solution for each piglet once a day. For cell culture assays, the culture supernatant of L. reuteri 15007 was reserved for subsequent treatment with a $10 \%(\mathrm{v} / \mathrm{v})$ concentration. The centrifugal cells were washed three times in phosphate-buffered saline (PBS), and then resuspended in $1 \mathrm{~mL}$ PBS. Finally, $200 \mu \mathrm{L}$ of bacterial resuspension solution was immediately used to treat cell cultures with a final concentration of $3 \times 10^{7} \mathrm{CFU} / \mathrm{mL}$ according to a preliminary test (data not shown).

\section{Animals and experimental design}

Twelve male Yorkshire $\times$ Landrace piglets which had been allowed to obtain colostrum from their dam for $48 \mathrm{~h}$ after birth were obtained from a commercial pig farm and transported to the Laboratory of Animal Metabolism at China Agricultural University (Beijing, China).

The piglets were individually housed in stainless steel cages $\left(1.4 \times 0.45 \times 0.6 \mathrm{~m}^{3}\right)$ in a temperature controlled nursery room $\left(33 \pm 1^{\circ} \mathrm{C}, 40 \%-60 \%\right.$ relative humidity). On the third day of life, piglets were trained to suckle from pacifier bottles filled with milk replacer (Rosalac Instant, Bonilait Proteins, France). The milk replacer provided $45 \%$ lactose, $21.5 \%$ protein, $18.7 \%$ fat, $9.8 \%$ ash, $1.7 \%$ lysine, and sufficient vitamins and minerals to meet nutrient requirements. The milk replacer was dissolved in warm boiled water (w/v 1:5) to provide a similar dry matter concentration as sow's milk. All the piglets were artificially fed every $4 \mathrm{~h}$. On day four (equivalent to the first day of the trial), the piglets with an average body weight of $2.00 \pm 0.31 \mathrm{~kg}$ were assigned into 2 groups with 6 piglets per treatment (a control group and a $L$. reuteri 15007 group) in a randomized complete block design according to their initial body weight. Each piglet in the $L$. reuteri 15007 group was orally administered with $6 \times 10^{9}$ CFU L. reuteri 15007 dissolved in $3 \mathrm{~mL} 0.1 \%$ sterile peptone solution at a fixed time every day for 14 days, while the piglets in the control group were given the same volume of $0.1 \%$ sterile peptone solution.

On the morning of day 15, piglets were euthanized after an overnight fast and their abdominal cavities were opened to remove the gastrointestinal tract. The small intestine was carefully dissected from the mesentery and $5 \mathrm{~cm}$ segments of the jejunum and ileum were gently flushed with $0.9 \%$ physiological saline. Then the intestinal segments were frozen in liquid nitrogen and stored at $-80^{\circ} \mathrm{C}$ for further analysis.

\section{Cell culture and treatment}

IPEC-J2, a porcine intestinal epithelial cell line, was kindly provided by Dr. Bruce Schultz from Kansas State University (Manhattan, KS). IPEC-J2 cells were cultured in 6-well plates in DMEM/F12 medium (Thermo, Waltham, MA), supplemented with $5 \%$ fetal bovine serum (Gibco, Carlsbad, CA), $5 \mu \mathrm{g} / \mathrm{L}$ epidermal growth factor (ScienCell, Carlsbad, CA) and 0.1\% 1X insulintransferrin-sodium (ScienCell, Carlsbad, CA) at $37^{\circ} \mathrm{C}$ in a humidified $5 \% \mathrm{CO}_{2}$ atmosphere. The culture was changed every other day.

TEER measurements were performed using a Millicell Electrical resistance system (Millipore, Billerica, MA). IPEC-J2 cells were seeded on the millicell membrance (12-wells, Millipore, Billerica, MA) cell inserts (Costar, Corning Inc., NY) at a density of $7 \times 10^{4} / \mathrm{cm}^{2}$ and determined to be confluent at a TEER value of $>1 \mathrm{kOhm} \times \mathrm{cm}^{2}$. When monolayer of cells was completely differentiated, cells were treated with $3 \times 10^{7} \mathrm{CFU} / \mathrm{mL}$ of $L$. reuteri $\mathrm{I} 5007$ for $0,2,4,6,8$ and $10 \mathrm{~h}$ and the TEER was measured respectively.

For measurements of inflammatory cytokine and $\mathrm{TJ}$ protein expression, IPEC-J2 cells were cultured in 6-well plates for complete confluence. Cells in each well were treated with $2 \mathrm{~mL}$ new medium containing $200 \mu \mathrm{L}$ of $L$. reuteri 15007 resuspension solution (with a final concentration of $3 \times 10^{7} \mathrm{CFU} / \mathrm{mL}$ ) or its culture supernatant which had no bacteria in it (diluted 1:10 in basal medium) for $2 \mathrm{~h}$. After rinsing in PBS three times, medium was then replaced with new medium containing $1 \mu \mathrm{g} / \mathrm{mL}$ LPS (E. coli 055:B5, Sigma, St. Louis, MO) based on the results of a preliminary test (data not 
shown). After 1, 4, 8, 12, or $24 \mathrm{~h}$, cells were collected to extract total RNA and protein for follow-up studies. All experiments were repeated three times with duplicate wells within each individual run.

\section{RNA isolation and expression analysis by real-time PCR} Total RNA was isolated from the cells using a RNeasy kit (Qiagen, Hilden, Germany) according to the manufacturer's instruction. RNA quality and quantity were determined by gel electrophoresis and a NanoDrop Spectrophotometer (P330, Implen, Germany). Subsequently, $1 \mu \mathrm{g}$ RNA was reverse-transcribed to complementary DNA (cDNA) using a PrimeScript 1st Strand cDNA Synthesis Kit (Takala, Ostu, Japan) according to the manufacturer's instructions. The gene-specific primer sequences are given in Table 1. Real-time PCR was performed using an Applied Biosystems 7500 Real-Time PCR System (Applied Biosystems, Singapore) with SYBR Green PCR Master Mix (Takala, Ostu, Japan), containing $\mathrm{MgCl}_{2}$, dNTP and Hotstar Taq polymerase. Briefly, copy numbers were calculated relative to a dilution series $\left(1: 10^{7}\right.$ to $\left.1: 1\right)$ of the respective reference plasmids which contained the cloned RT-PCR products obtained with these primers. The PCR system consisted of $5.0 \mu \mathrm{L}$ of YBR Green qPCR Mix, $1.0 \mu \mathrm{L}$ of cDNA, $0.25 \mu \mathrm{mol}$ of each primer, and $3.6 \mu \mathrm{L}$ of double distilled water in a final volume of $20 \mu \mathrm{L}$. Each sample was determined in triplicate and the housekeeping gene, $\beta$-actin, was used as the internal standard for the PCR reaction.

\section{Extraction of protein and immunoblotting}

Total protein was extracted from the intestinal tissues or IPEC-J2 cells using lysis buffer $(150 \mathrm{mM} \mathrm{NaCl}, 1 \%$ Triton $\mathrm{X}-100,0.5 \%$ sodium deoxycholate, $0.1 \%$ SDS, $50 \mathrm{mM}$ Tris- $\mathrm{HCl}$ at $\mathrm{pH} 7.4$, plus a protease inhibitor cocktail purchased from Applygene, Beijing, China). Briefly, $0.02 \mathrm{~g}$ of each frozen jejunum and ileum sample were powdered

Table 1 Primers used for real-time PCR

\begin{tabular}{|c|c|c|c|c|}
\hline Genes & Primers & Sequences (5'-3') & Size (bp) & $\operatorname{Tm}\left({ }^{\circ} \mathrm{C}\right)$ \\
\hline \multirow[t]{2}{*}{ TNF-a } & Forward & ATTCAGGGATGTGTGGCCTG & 120 & 62 \\
\hline & Reverse & CCAGATGTCCCAGGTTGCAT & & \\
\hline \multirow[t]{2}{*}{ IL-6 } & Forward & TGGATAAGCTGCAGTCACAG & 109 & 54 \\
\hline & Reverse & ATTATCCGAATGGCCCTCAG & & \\
\hline \multirow[t]{2}{*}{ Claudin-1 } & Forward & GCAGCAGCTTCTTGCTTCTC & 664 & 58 \\
\hline & Reverse & CTGGCATTGACTGGGGTCAT & & \\
\hline \multirow[t]{2}{*}{ Occludin } & Forward & ATCAACAAAGGCAACTCT & 157 & 50 \\
\hline & Reverse & GCAGCAGCCATGTACTCT & & \\
\hline \multirow[t]{2}{*}{ ZO-1 } & Forward & GAGTTGATAGTGGCGTT & 298 & 50 \\
\hline & Reverse & GTGGGAGGATGCTGTTGT & & \\
\hline \multirow[t]{2}{*}{$\beta$-actin } & Forward & TGCGGGACATCAAGGAGAAG & 216 & 60 \\
\hline & Reverse & AGTTGAAGGTGGTCTCGTGG & & \\
\hline
\end{tabular}

under liquid nitrogen, and lysed in lysis buffer containing protease inhibitors. IPEC-J2 cells in each well were scraped into $100 \mu \mathrm{L}$ of ice-cold lysis buffer containing protease inhibitors and then incubated on ice for $30 \mathrm{~min}$. The lysed samples were centrifuged at $10,000 \times g$ for $5 \mathrm{~min}$ at $4^{\circ} \mathrm{C}$ and the supernatant was collected. Total protein concentrations were determined using a BCA Protein Assay Kit (Pierce, Rockford, IL). Equal amounts of proteins $(30 \mu \mathrm{g})$ were electrophoresed on SDS polyacrylamide gel, and proteins were electrophoretically transferred onto polyvinylidene difluoride (PVDF) membranes (Millipore, Bedford, MA). These were then blocked in 5\% skim milk, and incubated (overnight at $4{ }^{\circ} \mathrm{C}$ ) with primary antibodies against claudin-1 (Sigma, St. Louis, MO), occludin (Abcam, Cambridge, United Kingdom), ZO-1 (Santa Cruz Biotechnology, Santa Cruz, CA), and $\beta$-actin (Cell Signaling Technology, Danvers, MA). The membranes were subsequently washed and incubated $(1 \mathrm{~h}$ at room temperature) with horseradish peroxidase-conjugated secondary antibodies (Zhongsan Gold Bridge, Beijing, China). The immunoblots were developed with the Western blot Luminence Reagent (Santa Cruz Biotechnology, Santa Cruz, CA), and exposed by AlphaImager 2200 (Alpha Innotech, San Leandro, CA) automatically. Band densities were quantified using AlphaImager 2200 (Alpha Innotech, San Leandro, CA).

\section{Statistical analysis}

All data were statistically analyzed using SPSS Software Version 17. The statistical significance of differences of $i n-$ vivo data was determined by Student's $t$-test. Each piglet served as an experimental unit. One way analysis of variance (ANOVA) was used with Student-Neuman-Keuls (SNK) as a multiple comparsion test to analyse in-vitro data, except for data of TEER, which was analyzed by Student's $t$-test. A $P$ value $<0.05$ was considered significant. Results are expressed as mean \pm standard error of the mean (SEM).

\section{Abbreviations}

TJ: Tight junction; ZO-1: Zonula occluden-1; LPS: Lipopolysaccharide; CFU: Colony forming units; NHEK: Normal human epidermal keratinocytes; TEER: Transepithelial electrical resistance.

\section{Competing interests}

The authors declare that they have no competing interests.
Authors' contributions

$\mathrm{FY}, \mathrm{AW}, \mathrm{XZ}$ and SQ participated in the design of the study. FY and $\mathrm{HL}$ carried out the experiments. $\mathrm{CH}$ and $\mathrm{XZ}$ designed the primers. FY analyzed data and wrote the manuscript. AW, XZ, and SQ edited and revised manuscript. All authors read and approved the final manuscript.

\section{Acknowledgements}

We acknowledge financial support from Special Fund for Agro-scientific Research in the Public Interest (No. 201403047), the National Natural Science Foundation of China (No: 31420103908), and the National Basic Research Program of China (973 Program, No. 2012CB124702, 2013CB117302). 


\section{Author details}

'State Key Laboratory of Animal Nutrition, China Agricultural University, Beijing 100193, China. ${ }^{2}$ Weifang Business Vocational College, Zhucheng 262234, China.

\section{Received: 14 August 2014 Accepted: 4 February 2015} Published online: 15 February 2015

\section{References}

1. Maragkoudakis PA, Chingwaru W, Gradisnik L, Tsakalidou E, Cencic A. Lactic acid bacteria efficiently protect human and animal intestinal epithelial and immune cells from enteric virus infection. Int J Food Microbiol. 2010;141 Suppl 1:91-7.

2. Clayburgh DR, Shen L, Turner JR. A porous defense: the leaky epithelial barrier in intestinal disease. Lab Invest. 2004;84(3):282-91.

3. Anderson JM, Van Itallie CM, Fanning AS. Setting up a selective barrier at the apical junction complex. Curr Opin Cell Biol. 2004;16(2):140-5.

4. Tsukita SH, Furuse M, Itoh M. Multifunctional strands in tight junctions. Nat Rev Mol Cell Biol. 2001;2(4):285-93.

5. Anderson JM. Molecular structure of tight junctions and their role in epithelial transport. News Physiol Sci. 2001;16:126-30.

6. Groschwitz KR, Hogan SP. Intestinal barrier function: molecular regulation and disease pathogenesis. J Allergy Clin Immunol. 2009;124(1):3-20.

7. Anderson JM, Stevenson BR, Jesaitis LA, Goodenough DA, Mooseker MS. Characterization of ZO-1, a protein component of the tight junction from mouse liver and Madin-Darby canine kidney cells. J Cell Biol. 1988;106 (4):1141-9.

8. Furuse M, Fujita K, Hiiragi T, Fujimoto K, Tsukita S. Claudin-1 and -2: Novel integral membrane proteins localizing at tight junctions with no sequence similarity to occludin. J Cell Biol. 1998;141(7):1539-50.

9. Furuse M, Itoh M, Hirase T, Nagafuchi A, Yonemura S, Tsukita S, et al. Direct association of occludin with ZO-1 and its possible involvement in the localization of occludin at tight junctions. J Cell Biol. 1994;127(6 Pt 1):1617-26.

10. $\mathrm{Hu} \mathrm{CH}$, Xiao K, Luan ZS, Song J. Early weaning increases intestinal permeability, alters expression of cytokine and tight junction proteins, and activates mitogen-activated protein kinases in pigs. J Anim Sci. 2013;91 (3):1094-101.

11. FAO/WHO. Health and nutritional properties of probiotics in food including powder milk with live lactic acid bacteria, Report of a Joint FAO/WHO Expert Consultation on Evaluation of Health and Nutritional Properties of Probiotics in Food including Powder Milk with Live Lactic Acid Bacteria, Córdoba, Argentina. 2001 [http:www.who.int/foodsafety/publications/ fs_management/en/probiotics.pdf]

12. Stella AV, Paratte R, Valnegri L, Cigalino G, Soncini G, Chevaux E, et al. Effect of administration of live Saccharomyces cerevisiae on milk production, milk composition, blood metabolites, and faecal flora in early lactating dairy goats. Small Ruminant Res. 2007;67(1):7-13.

13. Wang AN, Cai CJ, Zeng XF, Zhang FR, Zhang GL, Thacker PA, et al. Dietary supplementation with Lactobacillus fermentum 15007 improves the anti-oxidative activity of weanling piglets challenged with diquat. J Appl Microbiol. 2013;114(6):1582-91.

14. Vizoso Pinto MG, Rodriguez Gómez M, Seifert S, Watzl B, Holzapfel WH, Franz CM. Lactobacilli stimulate the innate immune response and modulate the TLR expression of HT29 intestinal epithelial cells in vitro. Int J Food Microbiol. 2009;133(1-2):86-93.

15. Liu Y, Fatheree NY, Mangalat N, Rhoads JM. Human-derived probiotic Lactobacillus reuteri strains differentially reduce intestinal inflammation. Am J Physiol Gastrointest Liver Physiol. 2010;299(5):G1087-96.

16. Meijer BJ, Dielman LA. Probiotics in the treatment of human inflammatory bowel diseases: Update 2011. J Clin Gastroenterol. 2011:45:S139-44.

17. Ukena SN, Singh A, Dringenberg U, Engelhardt R, Seidler U, Hansen W, et al. Probiotic Escherichia coli Nissle 1917 inhibits leaky gut by enhancing mucosal integrity. PLoS One. 2007;2(12):e1308.

18. Pagnini C, Saeed R, Bamias G, Arseneau KO, Pizarro TT, Cominelli F. Probiotics promote gut health through stimulation of epithelial innate immunity. Proc Natl Acad Sci. 2010;107(1):454-9.

19. Chow J. Probiotics and prebiotics: a brief overview. J Ren Nutr. 2002;12 (2):76-86.

20. Shah NP. Functional cultures and health benefits. Int Dairy J. 2007;17 (11):1262-77.
21. Corridoni D, Pastorelli L, Mattioli B, Locovei S, Ishikawa D, Arseneau KO, et al Probiotic bacteria regulate intestinal epithelial permeability in experimental ileitis by a TNF-dependent mechanism. PLoS One. 2012;7(7):e42067.

22. Miyauchi E, O'Callaghan J, Butto LF, Hurley G, Melgar S, Tanabe S, et al. Mechanism of protection of transepithelial barrier function by Lactobacillus salivarius: strain dependence and attenuation by bacteriocin production. Am J Physiol Gastrointest Liver Physiol. 2012;303(9):G1029-41.

23. Seth A, Yan F, Polk DB, Rao RK. Probiotics ameliorate the hydrogen peroxide-induced epithelial barrier disruption by a PKC- and MAP kinase-dependent mechanism. Am J Physiol Gastrointest Liver Physiol. 2008;294(4):G1060-9.

24. Shornikova AV, Casas IA, Mykkanen H, Salo E, Vesikari T. Bacteriotherapy with Lactobacillus reuteri in rotavirus gastroenteritis. Pediatr Infect Dis J. 1997;16 (12):1103-7.

25. Dicksved J, Schreiber O, Willing B, Petersson J, Rang S, Phillipson M, et al. Lactobacillus reuteri maintains a functional mucosal barrier during DSS treatment despite mucus layer dysfunction. PLoS One. 2012;7(9):e46399.

26. Huang CH, Qiao SY, Li DF, Piao XS, Ren JP. Effects of Lactobacilli on the performance, diarrhea incidence, VFA concentration and gastrointestinal microbial flora of weaning pigs. Asian-Aust J Anim Sci. 2004;17(3):401-9.

27. Li XJ, Yue LY, Guan XF, Qiao SY. The adhesion of putative probiotic lactobacilli to cultured epithelial cells and porcine intestinal mucus. J Appl Microbiol. 2008;104(4):1082-91.

28. Liu H, Zhang J, Zhang SH, Yang FJ, Thacker PA, Zhang GL, et al. Oral administration of Lactobacillus fermentum 15007 favors intestinal development and alters the intestinal microbiota in formula-fed piglets. J Agric Food Chem. 2014;62(4):860-6.

29. Wang AN, Yi XW, Yu HF, Dong B, Qiao SY. Free radical scavenging activity of Lactobacillus fermentum in vitro and its antioxidative effect on growingfinishing pigs. J Appl Microbiol. 2009;107(4):1140-8.

30. Yu HF, Wang AN, Li XJ, Qiao SY. Effect of viable Lactobacillus fermentum on the growth performance, nutrinent digestibility and immunity of weaned pigs. J Anim Feed Sci. 2008;17(1):61-9

31. Hou C, Wang Q, Zeng X, Yang F, Zhang J, Liu H, et al. Complete genome sequence of Lactobacillus reuteri 15007, a probiotic strain isolated from healthy piglet. J Biotechnol. 2014:179:63-4.

32. Resta-Lenert S, Barrett KE. Live probiotics protect intestinal epithelial cells from the effects of infection with enteroinvasive Escherichia coli (EIEC). Gut. 2003;52(7):988-97

33. Jijon $H$, Backer J, Diaz $H$, Yeung $H$, Thiel D, McKaigney C, et al. DNA from probiotic bacteria modulates murine and human epithelial and immune function. Gastroenterology. 2004;126(5):1358-73.

34. Karczewski J, Troost FJ, Konings I, Dekker J, Kleerebezem M, Brummer RJ, et al. Regulation of human epithelial tight junction proteins by Lactobacillus plantarum in vivo and protective effects on the epithelial barrier. Am J Physiol Gastrointest Liver Physiol. 2010;298(6):G851-9.

35. Zareie M, Johnson-Henry K, Jury J, Yang P, Nga B, McKay DM, et al. Probiotics prevent bacterial translocation and improve intestinal barrier function in rats following chronic psychological stress. Gut. 2006;55(11):1553-60.

36. Patel RM, Myers LS, Kurundkar AR, Maheshwari A, Nusrat A, Lin PW. Probiotic bacteria induce maturation of intestinal claudin 3 expression and barrier function. Am J Pathol. 2012;180(2):626-35.

37. Johnson GB, Brunn GJ, Samstein B, Platt JL. New insight into the pathogenesis of sepsis and the sepsis syndrome. Surgery. 2005;137(4):393-5.

38. Lin YP, Thibodeaux CH, Pena JA, Ferry GD, Versalovic J. Probiotic Lactobacillus reuteri suppress proinflammatory cytokines via c-Jun. Inflamm Bowel Dis. 2008;14(8):1068-83.

39. Jones SE, Versalovic J. Probiotic Lactobacillus reuteri biofilms produce antimicrobial and anti-inflammatory factors. BMC Microbiol. 2009;9:35.

40. Rachmilewitz D, Katakura K, Karmeli F, Hayashi T, Reinus C, Rudensky B, et al. Toll-like receptor 9 signaling mediates the anti-inflammatory effects of probiotics in murine experimental colitis. Gastroenterology. 2004;126(2):520-8.

41. Furuse M. Molecular basis of the core structure of tight junctions. Cold Spring Harb Perspect Biol. 2010;2(1):a2907.

42. Yi X, Wang Y, Yu FS. Corneal epithelial tight junctions and their response to lipopolysaccharide challenge. Invest Ophthalmol Vis Sci. 2000;41(13):4093-100.

43. Xie W, Wang HQ, Wang L, Yao CY, Yuan RX, Wu QP. Resolvin D1 reduces deterioration of tight junction proteins by upregulating $\mathrm{HO}-1$ in LPS-induced mice. Lab Invest. 2013;93(9):991-1000.

44. Mennigen R, Nolte K, Rijcken E, Utech M, Loeffler B, Senninger N, et al. Probiotic mixture VSL\#3 protects the epithelial barrier by maintaining tight 
junction protein expression and preventing apoptosis in a murine model of colitis. Am J Physiol Gastrointest Liver Physiol. 2009;296(5):G1140-9.

45. Khailova L, Dvorak K, Arganbright KM, Halpern MD, Kinouchi T, Yajima M, et al. Bifidobacterium bifidum improves intestinal integrity in a rat model of necrotizing enterocolitis. Am J Physiol Gastrointest Liver Physiol. 2009;297 (5):G940-9.

46. Sultana R, McBain AJ, O'Neill CA. Strain-dependent augmentation of tight-junction barrier function in human primary epidermal keratinocytes by Lactobacillus and Bifidobacterium lysates. Appl Environ Microbiol. 2013;79 (16):4887-94.

47. Kaper JB, Sperandio V. Bacterial cell-to-cell signaling in the gastrointestinal tract. Infect Immun. 2005;73(6):3197-209.

48. Hidalgo IJ, Raub TJ, Borchardt RT. Characterization of the human colon carcinoma cell line (Caco-2) as a model system for intestinal epithelial permeability. Gastroenterology. 1989;96(3):736-49.

49. Wilson G, Hassan IF, Dix CJ, Williamson R, Shah R, Mackey M, et al. Transport and permeability properties of human Caco-2 cells: An in vitro model of the intestinal epithelial cell barrier. J Control Release. 1990;11:25-40.

50. Sheth P, Delos SN, Seth A, LaRusso NF, Rao RK. Lipopolysaccharide disrupts tight junctions in cholangiocyte monolayers by a c-Src-, TLR4and LBP-dependent mechanism. Am J Physiol Gastrointest Liver Physiol. 2007;293(1):G308-18.

51. Yeung CY, Chiang CJ, Chan WT, Jiang CB, Cheng ML, Liu HL, et al. In vitro prevention of Salmonella lipopolysaccharide-induced damages in epithelial barrier function by various Lactobacillus strains. Gastroenterol Res Pract. 2013;2013:973209.

52. Yuki T, Yoshida H, Akazawa Y, Komiya A, Sugiyama Y, Inoue S. Activation of TLR2 enhances tight junction barrier in epidermal keratinocytes. J Immunol. 2011;187(6):3230-7.

53. Ewaschuk JB, Diaz H, Meddings L, Diederichs B, Dmytrash A, Backer J, et al. Secreted bioactive factors from Bifidobacterium infantis enhance epithelial cell barrier function. Am J Physiol Gastrointest Liver Physiol. 2008;295(5): G1025-34.

\section{Submit your next manuscript to BioMed Central and take full advantage of:}

- Convenient online submission

- Thorough peer review

- No space constraints or color figure charges

- Immediate publication on acceptance

- Inclusion in PubMed, CAS, Scopus and Google Scholar

- Research which is freely available for redistribution 